\title{
KARL MARX E ANTÔNIO GRAMSCI: TEORIAS QUE SE COMPLEMENTAM
}

\section{ARTIGO DE REVISÃO}

DIAS, Adailton Di Lauro ${ }^{1}$

DIAS, Deusira Nunes Di Lauro²

DIAS, Adailton Di Lauro. DIAS, Deusira Nunes Di Lauro. Karl Marx e Antônio Gramsci: Teorias que se complementam. Revista Científica Multidisciplinar Núcleo do Conhecimento. Ano 04, Ed. 07, Vol. 03, pp. 45-56. Julho de 2019. ISSN: 2448-0959

\section{RESUMO}

O presente artigo apresenta uma reflexão acerca da expressividade da obra do sociólogo italiano Antônio Gramsci bem como reflete sobre a influência de Karl Marx na sua teoria que, dentre outros aspectos, focava no cenário educacional da época. Por meio de seus escritos, Gramsci propõe uma escola igualitária e enfatiza o trabalho intelectual e manual com o objetivo de promover o indivíduo como um todo e obter, consequentemente, com esse processo, a transformação da sociedade. Seu conceito de escola entende que este ambiente não deve ser reduzido a um simples local onde o conhecimento é desenvolvido e adquirido, dessa forma abrange um grupo de estruturas do mercado de trabalho que ajudam no processo de compreensão desta escola. Com isso o artigo pretende, portanto, oferecer, no corpo geral da crítica

\footnotetext{
${ }^{1}$ Mestrando em Ciências da Educação (Grendal University). Especialista em Língua Inglesa (FIJ). Graduado em Letras (UNEB). Graduado em Português e Inglês pela Universidade Metropolitana de Santos - SP. Professor EBTT Port/Ing - IFRR.

${ }^{2}$ Mestranda em Ciências da Educação (Grendal University), pós graduada em Língua Portuguesa (Faculdade Vale do Cricaré), graduada em Língua Portuguesa e Literatura (Universidade Estadual da Bahia - UNEB).
} 
marxista, elementos e categorias que possibilitam a reformulação do conceito gramsciano de escola.

Palavras-chave: Gramsci, intelectual, escola, Karl Marx, transformação social.

\section{INTRODUÇÃO}

A contribuição do sociólogo Antônio Gramsci na expansão do referencial teórico marxista teve como enfoque os problemas emergentes no início do século passado, dentre eles a problemática educacional e cultural. Tal estudo conferiu-lhe o status de um dos mais expressivos e importantes pensadores do século $X X$, cuja influência e notoriedade sobre diversas áreas do conhecimento e da atividade política se faz presente até os dias atuais. Suas teorias e sua prática marcadas pela ruptura com qualquer tipo de dogmatismo que engessasse as ideias marxistas, procuraram recuperar o vigor da polêmica com outras concepções de mundo como método de crítica política e de produção do conhecimento. Embora tenham vivido em épocas diferentes, esses dois pensadores compartilharam anseios e visões de mundo semelhantes, embora cada um tenha sua identidade de pensamento bem delimitada por suas obras.

\section{INFLUÊNCIAS MARXISTAS NA OBRA DE ANTÔNIO GRAMSCI}

Embora nunca tenha publicado nenhum livro em vida, Antônio Gramsci (1891-1937) escreveu vários artigos em periódicos de partidos políticos e na imprensa, além de diversos cadernos de notas manuscritas durante sua prisão, imposta pelo regime fascista italiano, comandado por Mussolini. Tais escritos, conhecidos como "Cadernos do Cárcere", publicados postumamente representam, até hoje, uma rica fonte de reflexão filosófica, sociológica e política em relação à sociedade.

A competência adquirida por Gramsci para reformular o pensamento marxista fez com que se tornasse possível aderir a uma ideia mais condizente em relação à resposta marxista ao capitalismo contemporâneo. Com sua percepção, conseguiu adequar sua visão às características da sociedade europeia que contava com um capitalismo 
avançado na primeira metade do século XX. Segundo ele, para se chegar ao poder não basta ser eleito ou promover um golpe de Estado, é fundamental que uma outra batalha obtenha resultados positivos: ela não é física, mas sim intelectual, ou seja, para que se ganhe esta batalha é necessário persuadir e convencer para se obter, dessa forma, a aprovação social, escopo central desta batalha. Para tanto, é essencial que aquele que convence seja um intelectual. É a partir desse ponto que a escola passa a representar um papel de destaque, uma vez que é responsável pela formação intelectual dos indivíduos, por meio do acesso especial à cultura, razão pela qual tenha despertado em Gramsci uma preocupação com a configuração do sistema escolar do seu tempo.

Após analisar e observar que havia um conflito entre as dimensões da pedagogia do cultivo e a do treinamento, Gramsci concluiu e passou a defender que no mundo contemporâneo a ciência acabou por se dissimilar na vida cotidiana a partir de ações nunca antes praticadas, assim as atividades práticas tornaram-se complexas e especializadas. Considerando este contexto, Gramsci aderiu as teorias que pensavam as superestruturas (órgãos reguladores da esfera social) para repensar e reformular o conceito marxista de Estado. Nesse sentido, passou a entender o Estado como um mecanismo de repressão e violência que age a partir, principalmente, da política para persuadir e convencer a sociedade a aderir determinadas condutas sociais a partir dos seus aparelhos de repressão e controle.

Os conceitos de sociedade civil e de hegemonia permitem pensar no problema da educação a partir de um novo enfoque: permitem elaborar um conceito emancipatório de educação, em que uma pedagogia do oprimido pode assumir força política, ao lado da conceituação da educação como instrumento de dominação e reprodução das relações de produção capitalista (GRAMSCI, 1999, p.31)

De acordo com Gruppi (2000:03), o conceito de hegemonia foi apresentado por Gramsci como algo que opera não apenas sobre a estrutura econômica e sobre a 
organização política da sociedade, mas também sobre o modo de pensar, sobre as orientações ideológicas e inclusive sobre o modo de conhecer.

Assim como Marx, Gramsci atuou como um intelectual que se debruçava, sobretudo, nos conceitos relacionados com a política para a elaboração de críticas. Um dos pontos de encontro entre os dois autores é que buscavam refletir, analisar e criticar as regras e normas que faziam com que o capitalismo tomasse grandes proporções.

Segundo Coutinho, a grande "descoberta" de Marx (e Engels) na esfera política concentrou-se na defesa de que a configuração das classes sociais é um fenômeno, essencialmente, estatal. Porém Marx não conheceu o capitalismo desenvolvido anos mais tarde no mundo ocidental. Dessa forma, desconheceu alguns dos efeitos provocados por este capitalismo, como o surgimento dos sindicatos, dos partidos massivos, a eleição de caráter parlamentar bem como a conquista do sufrágio universal. Por essa razão, Gramsci amplia a análise de Marx ao introduzir como novidade a hegemonia que agora possui tanto uma configuração própria quanto especificidades e características que fazem com que ela se manifeste em diversas esferas. Assim, o Estado, na perspectiva de Gramsci, devido a tal ampliação, está mais sujeito a responder aos conflitos que tomam forma nas classes que dão forma à sociedade.

Para Marx, a natureza é toda a apropriação que o homem faz dela, além da sociedade em que vive. Já a práxis é a mediação dessa relação existente entre homem e natureza, materializada pelo processo de produção que the define a utilidade e expressa o poder de transformação do ambiente externo pelo homem, representado pela natureza e pelo meio social no qual está inserido. Ainda segundo Marx, a práxis deve ser entendida como um exercício inerente ao ser humano e possui como característica principal a prática e a crítica, dessa forma, é uma atividade sensível, logo, subjetiva, que é percebida e movida, de forma consciente, pelo homem.

No entanto, Gramsci conceitua a práxis com um significado diferenciado: para ele, a prática da atividade humana deve ser encarada, essencialmente, como um processo 
cuja a história do indivíduo é construída, ou seja, um processo onde a identidade toma forma. No entanto, a práxis, por sua vez, constitui-se a partir da interferência humana na natureza, tendo-se como objetivo, sobretudo, alcançar propósitos e satisfazer necessidades. $O$ autor continua afirmando que esta é uma atividade, naturalmente, racional. Entretanto, para ele, há um novo elemento que age neste processo de constituição de identidade a partir das práxis: a luta de classes. Nesse sentido, Gramsci aponta que o sujeito deixa de intervir, de forma harmônica e saudável, no meio em que se vive. Em detrimento de tais fatores, as relações passam a se constituir de forma conflituosa por meio da luta de classes.

Embora Marx e Gramsci não tenham o aspecto educacional como foco de seus escritos, ambos entendem e concordam que as diretrizes para que se obtenha uma educação mais humanizada devem partir, sobretudo, de aspectos reais do cotidiano desses alunos, ou seja, as condições de existência organizadas pelos seres humanos precisam ser consideradas neste processo de ensino e aprendizagem. Assim, os homens travam determinados tipos de relações sociais de produção que desempenham um duplo papel transformador: humanizar o meio em que se vive e as relações sociais ao mesmo tempo.

\section{A REFORMA INTELECTUAL PROPOSTA POR GRAMSCI}

Antes de se desenvolver um conceito/ideia de reforma intelectual, faz-se necessário e oportuno mencionar aspectos importantes para o entendimento de tal definição, a saber: a hegemonia e o mundo em que se habita. Dessa forma, para Gramsci, a hegemonia deve ser encarada como uma ideia de dominação frente a um determinado grupo. Esse processo se dá, essencialmente, por meio da persuasão, objetivando-se chegar a um consenso. Utiliza-se argumentos oriundos, principalmente, das esferas econômica e política, entretanto, eles revelam, também, concepções de mundo, visto que atuam como fatores culturais e morais que dão forma a sociedade.

Partindo desse pressuposto, Gramsci defendia a ideia de que a superestrutura (sociedade civil e sociedade política) exercia uma enorme influência sobre a estrutura 
(relações sociais). Entende-se que as teorias elaboradas pelos pensadores modificam o pensamento humano, e, consequentemente, as suas ações bem como a sua relação com outras esferas, sobretudo a política e a que diz respeito aos meios de produção. Os intelectuais e as ideias que divulgam alteram a maneira como os homens se relacionam com a política e com os meios de produção. Em relação ao papel do proletariado, este, por sua vez, tentava conquistar espaço neste processo de hegemonização de ideias. Deve-se frisar, também, que o intelectual não vai de encontro com as teorias mecanicistas e deterministas sobre a hegemonia, pois, para ele, não deve ser vista como uma superestrutura unilateral, mas sim como um espaço onde relações recíprocas dão forma ao fenômeno por meio do conflito de vozes que tentam impor a sua hegemonia nas estruturas.

Aí reside a potencialidade do conceito de Gramsci: reconhecer que a autoridade e suas diferentes formas de coerção envolvem estratégias muito mais sofisticados que a violência. Nesse sentido, o crítico defende que o Estado contempla todas as atividades de caráter prático ou teórico cuja a classe dominadora, a todo momento, justifica e, por meio de aparelhos, tenta manter os espaços sob o seu domínio. Entretanto, obtém, de forma geral, o consentimento da população. Surge, como resposta, a luta proposta de Gramsci. Todavia, é um processo lento que requer paciência bem como um espírito interventivo. Deve-se entender que a

[...] iniciativa dos sujeitos políticos coletivos e a capacidade de fazer política, de envolver grandes massas na solução de seus próprios problemas, de lutar cotidianamente pela conquista de espaços e posições, sem perder de vista o objetivo final, ou seja, o de promover transformações de estruturas que ponham fim a formação econômicosocial capitalista (COUTINHO, C. N, p. 155).

Nesse sentido, a teoria desenvolvida por Gramsci viabilizava a ocupação metódica e sistemática dos trabalhadores. Para tanto, considerava-se os espaços ampliados de maneira estratégica para a expansão da sociedade civil diante da esfera política que tomava forma, principalmente, nas ações de intervenção do Estado. Entretanto, este 
movimento fez com que fosse possível a conquista do poder político pela classe proletária. Essa conquista do poder político pode ser descrita nas seguintes palavras de Gramsci:

Criar uma nova cultura não significa apenas fazer individualmente descobertas 'originais'; significa também e sobretudo, difundir criticamente verdades já descobertas, 'socializá-las' por assim dizer; e, portanto, transformá-las em bases de ações vitais, em elemento de coordenação e de ordem intelectual e moral. O fato de que uma multidão de homens seja conduzida a pensar coerentemente e de maneira unitária a realidade presente é um fato 'filosófico' bem mais importante e 'original' do que a descoberta, por parte de um 'gênio' filosófico, de uma nova verdade que permaneça como patrimônio de pequenos grupos intelectuais (GRAMSCI, 1999, p.95-96).

Conforme propõe Gramsci, para construir essa concepção crítica, coerente e unitária de mundo, as novas teorias assumem um papel decisivo. Assim, o denominado intelectual orgânico é encarado como o responsável por mediar a vontade dos grupos sociais. Tem como objetivo reconstruir a hegemonia, sendo necessário, para tanto, o uso da persuasão, para que a reconstrução apareça de forma ativa na vida cotidiana. O consenso, nessa perspectiva, deve tomar proporções de forma espontânea para que o poder revolucionário possa ser efetivamente conservado.

Para Gramsci (1978), a dimensão histórica bem como a variação política que desmorona as esferas da sociedade regida por classes faz com que seja necessária a adesão da busca contínua pelo alcance de uma determinada posição. Nesse contexto, precisa ser realizada, em um primeiro momento, no plano das ideias. Dessa forma, torna-se necessária a ampliação cultural das classes populares. Para tanto, é essencial que esse público passe por um processo de conscientização crítica para que a revolução não seja um fenômeno passivo mas sim algo massivo, ou seja, para que muitas pessoas sejam conduzidas a aderir a uma outra hegemonia bem como para que se sintam instigadas a participar de lutas coletivas para que haja uma nova 
configuração da sociedade em que se vive. Assim, a sociedade precisa ser vista como um espaço sempre em transição. Nessa perspectiva, Gramsci aponta que essa transição tem como escopo a construção de uma sociedade qualitativa em todas as dimensões da vida, devendo o homem transicionar das ideias pré-históricas para uma nova concepção de valores sociais e humanos. Tal valorização resultaria em uma sociedade mais humanizada bem como haveria uma maior emancipação da humanidade.

\section{ESCOLA TRANSFORMADORA}

Enquanto boa parte dos estudiosos dos problemas educacionais seguidores da orientação marxista afirmam que a escola tem como função reproduzir as desigualdades sociais ao mesmo tempo que reproduzem os valores da superestrutura, ou seja, aqueles dominantes. Gramsci possui uma visão distinta sobre a escola e sua função: segundo ele, a escola tem o poder de se remodelar, todavia, para isso, precisa ceder, às classes dominadas, as ferramentas necessárias para que após um processo de conscientização e luta constantes, os dominados possam inverter a situação e governar aqueles que os comandam. Nesse contexto, o intelectual não contrasta o caráter reprodutor da escola, pois defende que essa, em muitas das vezes, instiga o conformismo e a estabilidade das ideias. No entanto, por possuir um pensamento engajado com a transformação da sociedade, Gramsci defende a escola deve atuar como um ambiente capaz de trazer esclarecimentos e contribuições para a ascensão cultural das massas.

Sendo assim, a escola unitária de formação humanista ou de cultura geral, defendida por Gramsci, precisa se configurar como a principal responsável pela inserção dos jovens em todas as dimensões da vida social. Contudo, o processo deve ser gradual, pois é preciso que esses alunos atinjam a uma maturidade e criticidade para que consigam pensar e agir de forma mais reflexiva, e, ao mesmo tempo, autônoma.

Gramsci tem como principal característica de sua produção teórica, portanto, a própria conceituação de como deve se caracterizar a sociedade. Dessa maneira, sua 
perspectiva sempre parte da elaboração de conceitos que devem auxiliar o proletariado a consolidar o poder sobre o conjunto de classes subalternas, para, assim, disputar a direção intelectual e moral do conjunto da sociedade, ações estas que projetam a tomada do poder político e a alteração da situação de dominação.

Nesse sentido, a escola unitária proposta por Gramsci requer do Estado um suporte que garanta financeiramente 0 acesso e a permanência do jovem na escola, sobretudo por meio da oferta de recursos didáticos e humanos capazes de viabilizar a ascensão desse jovem, passando, portanto, a representar-se no contexto da transformação da sociedade como um dos principais pilares dessa conquista. E, para ele, a relação pedagógica passa a ser concebida como experiência coletiva de emancipação que vai muito além dos muros da escola convencional:

[...] a relação pedagógica não pode ser limitada às relações especificamente "escolares", através das quais as novas gerações entram em contato com as antigas e absorvem suas experiências e seus valores historicamente necessários, "amadurecendo" e desenvolvendo uma personalidade própria, histórica e culturalmente superior. Esta relação existe em toda a sociedade no seu conjunto e em todo indivíduo com relação aos outros indivíduos, entre camadas intelectuais e não intelectuais, entre governantes e governados, entre elites e seguidores, entre dirigentes e dirigidos, entre vanguardas e corpos de exército (GRAMSCI, 1975, p.1331).

No entanto, deve-se ressaltar que, para Gramsci, o sentido lato conferido à atividade e à organização escolar não deve minimizar as particularidades do ambiente escolar, sobretudo os aspectos relacionados com o tempo, o espaço e com a formação de novas gerações nem deve tornar menos importante o seu papel no desenvolvimento da comunicação e na aquisição de conteúdo sobre as regras naturais bem como sobre aquelas produzidas na esfera social pelo homem. Gramsci entende e defende que a escola como um aparelho de conservação da hegemonia pode vir a assumir um papel determinante para a conquista do poder pelos grupos minoritários. 
[...] é a escola pública, laica, obrigatória e gratuita, aberta e garantida às crianças originárias de todas as classes sociais, que estudam as mesmas disciplinas, pelo mesmo currículo, por todas as séries ou graus que precedem o nível universitário, sem distinção entre formação humanista e formação profissional (MOCHCOVITCH, 1990, 67).

Em seus escritos, Gramsci não descarta a hegemonia, antes a considera essencial à luta de "hegemonias": ele sempre pensa no caráter transformador do meio social e não na mera reprodução dos conhecimentos prévios adotados socialmente. Propõe uma reflexão sobre como a hegemonia pode ser transformada por meio da ação da classe proletária e como essa, por sua vez, pode enraizar os seus valores sobre outras classes até então dominantes, pois parte-se do princípio de que uma visão de mundo coerente e homogênea consegue ser aderida por meio da realização de alianças sociais entre grupos. Este movimento é essencial para que a classe operária possa ganhar expressividade frente a hegemonia burguesa e, assim, reiterar os seus valores e serem menos passivas aos aparelhos dominantes (MOCHCOVITCH, 1990, 24). Gramsci enxerga a educação como um instrumento de luta essencial "para estabelecer uma nova relação hegemônica que permita constituir um novo bloco histórico sob a direção da classe fundamental dominada da sociedade capitalista."

Segundo Gramsci, cabe à escola a função social de desempenhar a ação docente de forma responsável e comprometida com as demandas exigidas pelo ser humano assim como pela sociedade como um todo. Nesse sentido, atua como um espaço necessário para o desenvolvimento e ampliação do conhecimento. Dessa forma, não pode atuar de forma limitadora e sim expansiva. Para tanto, é crucial trazer a realidade cotidiana para dentro das salas de aula, pois assim o aprendizado ocorre de forma mais fluida. Algumas estratégias podem ser acionadas como a elaboração de um currículo que integra as demandas sociais na apresentação dos conteúdos, de forma a contemplar as intrínsecas e essenciais necessidades do ser humano (formação holística), isto porque a projeção esperada de "ser humano" aspirada contempla especificidades que aparecem como um modelo, ou seja, como um tipo de currículo. 
Nesse contexto, é mister que a escola torne o cidadão consciente de todas as suas características potenciais, não subjugando ideias e oferecendo conhecimentos esclarecedores de maneira a possibilitar uma visão e leitura crítica dos fatos. Segundo Gramsci, para que isso aconteça, faz-se necessário que a ideologia ceda lugar ao verdadeiro conhecimento, dessa maneira, tanto o currículo quanto a sociedade serão verdadeiramente emancipados e libertos.

\section{UTOPIA OU SONHO POSSÍVEL?}

Partindo das reflexões e apontamentos de Gramsci, é possível concluir que ele se concentrou em pensar criticamente, principalmente, sobre um modelo de educação ideal para que os valores que dão forma a sociedade sejam transformados de maneira efetiva. Segundo ele, é por meio da ação pedagógica reflexiva e crítica que é possível chegar às mudanças pretendidas. Aponta, também, que o Estado deve ser visto como o principal agente responsável por mediar e aprimorar a educação por meio do oferecimento de recursos e ferramentas necessários para a ação docente. Para tanto, deve agir de forma ética bem como considerar as condições sociais, políticas e econômicas das classes populares ao elaborar políticas de intervenção.

A ética estatal, nesse contexto, interliga-se ao processo de emancipação da humanidade. Assim, parte-se da ideia de que o Estado não pode atuar como um educador enquanto este continuar a ser regido por concepções burguesas que não dão prioridade às exigências das classes menos favorecidas, pois, assim, prejudica a educação das massas populares. Gramsci aponta, nessa perspectiva, que é essencial a garantia, no mínimo, dos níveis mais básicos de ensino bem como a existência de uma escola de caráter formativo, seguindo, para tanto, à ideais democráticos. A escola democrática, por sua vez, deve ser assegurada a todos pelo Estado para que este possa ser considerado como ético e educativo.

Deve-se, mesmo que de forma abstrata, transformar a condição do cidadão de dominado em dominante (MOCHCOVITCH, 1990, p.56). Uma escola de liberdade e de livre iniciativa não pode ser caracterizada como um ambiente escravocrata e 
mecânica. Por estas razões e diante do cenário político mundial atual, torna-se, cada vez mais, urgente repensar as políticas públicas para que estas sirvam como possibilidade de mudanças nos seus mais diversos níveis (social, cultural, econômico e político), de forma a promover, continuamente, a necessidade da construção de uma sociedade mais justa para os cidadãos.

\section{CONSIDERAÇÕES FINAIS}

Diante de todo o material aqui exposto, o que se pode observar na sociologia de Gramsci é que ele propôs uma mudança dos ideais dominantes para os propostos pelo proletariado. Dessa forma, pensava e idealizava uma escola igualitária para todos. Para ele, o pensamento e a prática deveriam caminhar de forma conjunta e indissociada. Pode-se afirmar que a escola ideal de Gramsci é, para muitos, utópica, entretanto, essencial para a sanção das desigualdades sociais bem como para a criação de uma sociedade justa para todos. Nesse sentido, a escola, para o intelectual, é o principal meio para se chegar a mudança, sendo necessário, para tanto, articulala de forma libertadora dos moldes convencionais. Foi considerado por muitos pensadores como o "príncipe moderno", visto que atuou como principal mentor e difusor desta corrente da educação.

A ação da escola, todavia, precisa se consolidar de maneira formativa, assim precisa ser compreendida como parte integrante de um projeto revolucionário, assumindo, assim, uma importância fundamental na luta pelo fim da sociedade de classes. Em consonância com a ideia de Marx, contida na Crítica da Filosofia do Direito de Hegel, segundo a qual a teoria se transforma em força material tão logo se apodere das massas, Gramsci considerava essencial que as massas se apoderassem da filosofia da práxis (marxismo) como principal estratégia para se compreender e transformar a realidade social. Objetivava-se, principalmente, a ressignificação do papel da instituição escolar na elaboração de uma contra ideologia revolucionária. Dessa forma, pode-se concluir este estudo afirmando que a sua atuação se relaciona, ainda que de forma imediata, com as diversas possibilidades educativas contidas no próprio processo produtivo no contexto social. 


\section{REFERÊNCIAS BIBLIOGRÁFICAS}

FREITAG, B. Escola, Estado e Sociedade. São Paulo: Edart, 1977.

GONÇALVES, D. N; MACHADO, E. G; ALBUQUERQUE, J. L. C. A Interpretação da Teoria de Gramsci por Carlos Nelson Coutinho. Revista de Ciências Sociais, v. 35, n. 2, 2004.

GRAMSCI, A. Cadernos do Cárcere. Volume 1, Rio de Janeiro, Civilização Brasileira, 1999, p. 95 e 96.

Cadernos do Cárcere. Volume 2. Rio de Janeiro, Civilização Brasileira, 2000, p. 53.

. Os intelectuais e a organização da cultura. $8^{\mathrm{a}}$ ed. Rio de Janeiro: Civilização Brasileira, 1991.

A concepção dialética da história. $2^{\underline{a}}$ ed. Rio de Janeiro: Civilização Brasileira, 1978.

GRUPPI, L. O conceito de hegemonia em Gramsci. 4ª ed. Rio de Janeiro: Edições Graal, 2000.

JESUS, A. T. Educação e hegemonia no pensamento de Antônio Gramsci. São Paulo/Campinas: Cortez. Ed. UNICAMP, 1989.

JESUS, A. T. O pensamento e a prática escolar de Gramsci. Campinas: Autores associados, 1998.

KOHÁN, N. Gramsci e Marx: Hegemonia e poder na teoria marxista. Publicado em La Izquierda. Debate. 17 de março de 2001.

MOCHCOVITCH, L. G. Gramsci e a escola. São Paulo: Ática, 1988.

NOSELLA, P. A. A escola de Gramsci. Porto Alegre: Artes Médicas, 1990. 
Enviado: Junho, 2019.

Aprovado: Julho, 2019. 